\title{
CONF-950494--34
}

DOE/MC/30088-95/C0474

\section{High-Power Slim-Hole Drilling System}

Authors:

John H. Cohen

\section{Contractor:}

Maurer Engineering

2916 West T.C. Jester

Houston, Texas 77018

Contract Number:

DE-AC21-94MC30088

\section{Conference Title:}

Natural Gas RD\&D Contractor's Review Meeting

\section{Conference Location:}

Baton Rouge, Louisiana

\section{Conference Dates:}

April 4 - 6, 1995

\section{Conference Sponsor:}

Co-Hosted by Department of Energy (DOE)

Morgantown Energy Technology Center

Morgantown, West Virginia

and

Southern University and

Agricultural and Mechanical College

Baton Rouge, Louisiana 


\section{DISCLAIMER}

This report was prepared as an account of work sponsored by an agency of the United States Government. Neither the United States Government nor any agency thereof, nor any of their employees, makes any warranty, express or implied, or assumes any legal liability or responsibility for the accuracy, completeness, or usefulness of any information, apparatus, product, or process disclosed, or represents that its use would not infringe privately owned rights. Reference herein to any specific commercial product, process, or service by trade name, trademark, manufacturer, or otherwise does not necessarily constitute or imply its endorsement, recommendation, or favoring by the United States Government or any agency thereof. The views and opinions of authors expressed herein do not necessarily state or reflect those of the United States Government or any agency thereof.

This report has been reproduced directly from the best available copy.

Available to DOE and DOE contractors from the Office of Scientific and Technical Information, 175 Oak Ridge Turnpike, Oak Ridge, TN 37831; prices available at (615) 576-8401.

Available to the public from the National Technical Information Service, U.S. Department of Commerce, 5285 Port Royal Road, Springfield, VA 22161; phone orders accepted at (703) 487-4650. 


\section{DISCLAIMER}

Portions of this document may be illegible in electronic image products. Images are produced from the best available original document. 
CONTRACT INFORMATION

Contract Number

Contractor

Other Funding Sources

Contractor Project Manager

Principal Investigators

METC Project Manager

Period of Performance
DE-AC21-94MC30088

Maurer Engineering Inc.

2916 West T.C. Jester

Houston, Texas 77018

(713) 683-8227 (telephone)

(713) 683-6418 (telefax)

None

William J. McDonald, Ph.D.

John H. Cohen

John R. Duda

Sept. 30, 1994 to Sept 30, 1995

Schedule and Milestones

\begin{tabular}{|c|c|c|c|c|c|c|c|c|c|c|c|c|}
\hline \multirow{2}{*}{ TASKS } & \multicolumn{12}{|c|}{ FISCAL YEAR '95 PROGRAM SCHEDULE } \\
\hline & $\mathrm{O}$ & $\mathbf{N}$ & $\mathrm{D}$ & $\mathbf{J}$ & $\mathbf{F}$ & $\mathbf{M}$ & A & $\mathbf{M}$ & $\mathrm{J}$ & $\mathbf{J}$ & A & $\mathbf{S}$ \\
\hline 1. Design Motor & $\mathbf{x}$ & $\mathbf{x}$ & $\mathbf{x}$ & & & & & & & & & \\
\hline 2. Fabricate Motor & & & $\mathbf{x}$ & $\mathbf{x}$ & $\mathbf{x}$ & & & & & & & \\
\hline 3. Motor Tests & & & & & & $\mathbf{x}$ & $\mathbf{x}$ & $\mathbf{x}$ & & & & \\
\hline 4. Design TSP Bits & & & & & & & & $\mathbf{x}$ & $\mathbf{x}$ & & & \\
\hline 5. Fabricate Bits & & & & & & & & & $\mathbf{x}$ & & & \\
\hline 6. Drilling Tests & & & & & & & & & & $\mathbf{x}$ & $\mathbf{x}$ & $\mathbf{x}$ \\
\hline
\end{tabular}




\section{High-Power Slim-Hole Drilling System}

\section{OBJECTIVES:}

The objective of this project is to implement new high-power slim-hole motors and bits into field gas well drilling applications. Development of improved motors and bits is critical because rotating time constitutes the major cost of drilling gas wells.

Conventional motors drill most formations 2 to 3 times faster than rotary continuous coring systems due to greater power transfer to the drill bit. New high-power motors and large-cutter TSP bits being developed by Maurer Engineering, Inc. (MEI) drill 2 to 3 times faster than conventional motors. These slim-hole high-power motors and bits, which are ready for field testing on this DOE project, should reduce drilling costs by 20 to 40 percent in many areas.

\section{Phase I}

The objective of Phase I is to design, manufacture and laboratory test improved highpower slim-hole motors and large-cutter TSP bits. This work will be done in preparation for Phase II field tests.

\section{Phase II}

The objective of Phase II will be to field test the high-power motors and bits in Amoco's Catoosa shallow-test well near Tulsa, OK, and in deep gas wells. The goal will be to drill 2 to 3 times faster than conventional motors and to reduce the drilling costs by 20 to 40 percent over the intervals drilled.

\section{BACKGROUND INFORMATION:}

In the late 1950 s and 1960 s, over 3000 slim holes were drilled in oil and gas fields worldwide. These slim holes reduced well costs by 20 to 50 percent in many areas, primarily due to reduced rig and tubular costs. Although significant cost savings were achieved, larger holes were used predominantly in the ' 70 s and ' 80 s due to 1) short life of small-diameter roller bits, 2) high oil prices, and 3 ) the misconception that large holes were needed everywhere. Many companies are now re-examining the use of slim-hole drilling because improved slim-hole drilling motors equipped with advanced TSP and PDC bits have potential for reducing well costs by 40 to 60 percent in many areas.

\section{Basic Slim-Hole Drilling Systems}

There are currently three basic slim-drilling systems (see Figure 1) being utilized or developed.

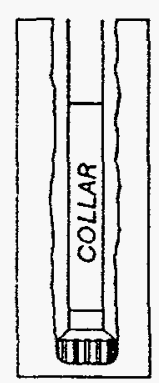

ROTARY

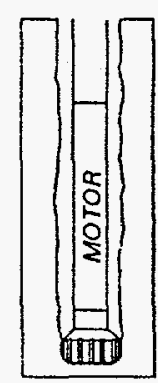

DOWNHOLE
MOTOR

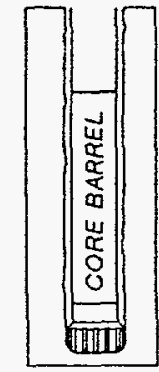

CONTINUOUS CORING
Figure 1. Basic Slim-Hole Drilling Systems 
Rotary slim-hole rigs rotate small diameter drill pipe at speeds of 300 to $800 \mathrm{rpm}$. Twist-offs of the small-diameter drill pipe are a major problem with this system.

Downhole Motor systems utilize slim-hole motors to rotate bits at speeds of 800 to $2000 \mathrm{rpm}$. They drill at high rates and eliminate drill string twist-off problems by eliminating drill string rotation.

Continuous Coring systems use slim-hole mining core barrels to continuously core entire wells. They are used in new drilling areas where geologists need cores to define geology.

\section{PROJECT DESCRIPTION:}

\section{Phase I - Design and Laboratory Tests}

During Phase I, MEI is designing and testing a slim-hole high-power drilling system that includes a downhole multi-lobe Moineau motor and a largecutter TSP bit.

The new 33/8-in. multi-lobe motor, capable of delivering twice the power of conventional motors will be used to drill slim-holes with $41 / 2$ - and $43 / 4$-in. diameter bits. Figure 2 shows key improvements that will be made to the motor.

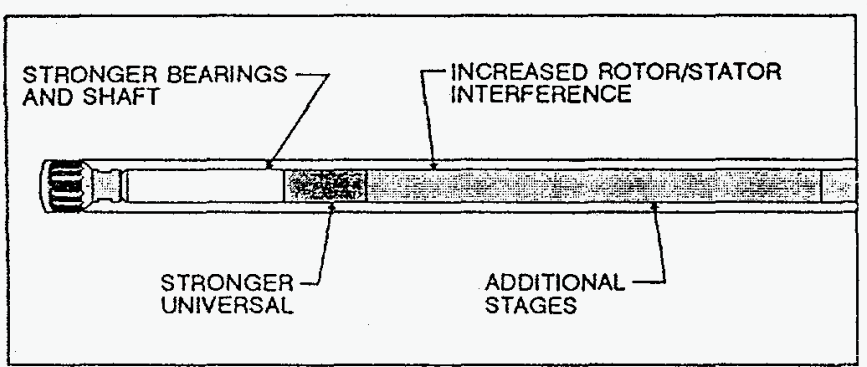

Figure 2. High-Power Motor Improvements
The power end of the motor will be manufactured from two standard Robbins \& Myers (R\&M) stators and a specially-machined, doublelength rotor. The lobe configuration will be $4 / 5$ as shown in Figure 3.

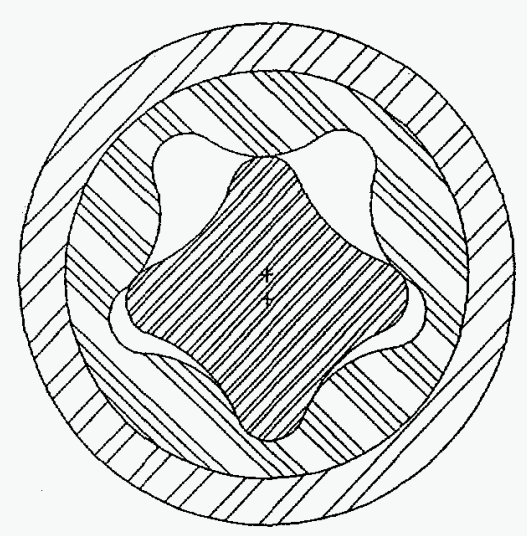

Figure 3. Motor Lobe Configuration

Due to its higher power, the motor must have a stronger bearing pack and stronger flex coupling. MEI will use the latest technologies to improve bearings and flex couplings for use in this motor.

The areas of improvement on the flex coupling include improved high-strength steels, lobe-cutting methods and a titanium flex shaft. MEI will select the best flex coupling for field testing.

The bearing pack improvements include improved high-strength steel for the drive shaf, metalon-metal radial bearings and stronger thrust bearings. The improved drive shaft will have a large bore to decrease pressure losses through the drive shaft and to allow increased flow through the motor, resulting in higher rotary speed, increased power, and improved hole cleaning.

The extra Moineau stages will permit higher pressure drop across the motor section, resulting in increased torque, higher power, increased weight-on- 
bit and increased drilling rate. The higher-than-normal bit loads will be absorbed by improved bearings in the bearing pack.

An engineering review will be conducted after the high-power slim-hole motor design drawings are completed. Problems found will be corrected and final manufacturing drawings will be prepared.

MEI will fabricate and test critical motor components to select the best design for use in the field motors. All manufactured components will be inspected for dimensional accuracy and material coupons will be used to insure correct heat treatment of all parts.

After all parts have been inspected, MEI will assemble and test the motor on the Drilling Research Center (DRC) motor dynamometer test stand shown in Figure 4.

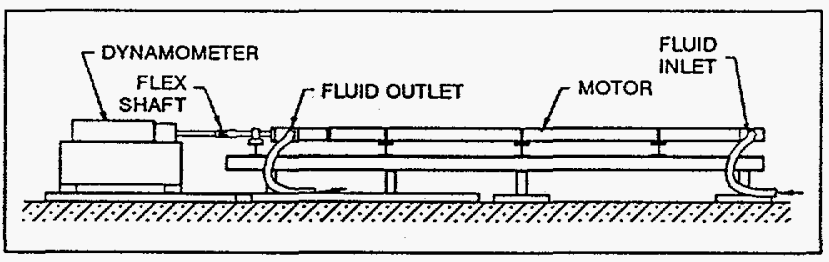

Figure 4. DRC Motor Dynamometer

Motor performance curves will be compared with theoretical calculations in preparation for field testing. The test stand will also be used to evaluate critical components such as flex couplings and flex shafts.

The second component of the slim-hole highpower drilling system is the large-cutter TSP (LCTSP) BIT. An earlier study showed that the majority of time in drilling a well is spent rotating the bit and tripping; therefore, the greatest reductions in time and cost can be obtained by increasing the penetration rate. As a result, these advanced TSP bits were developed.

PDC bits have made a major improvement in oil and gas drilling during the past ten years, especially in softer shales where the PDC bits are very effective. However, the PDC cutters deteriorate and fail in hard rock due to severe temperature limitations. PDC cutters fail at $700^{\circ} \mathrm{C}$, whereas TSP cutters operate effectively at temperatures up to $1200^{\circ} \mathrm{C}$ (Fig. 5).

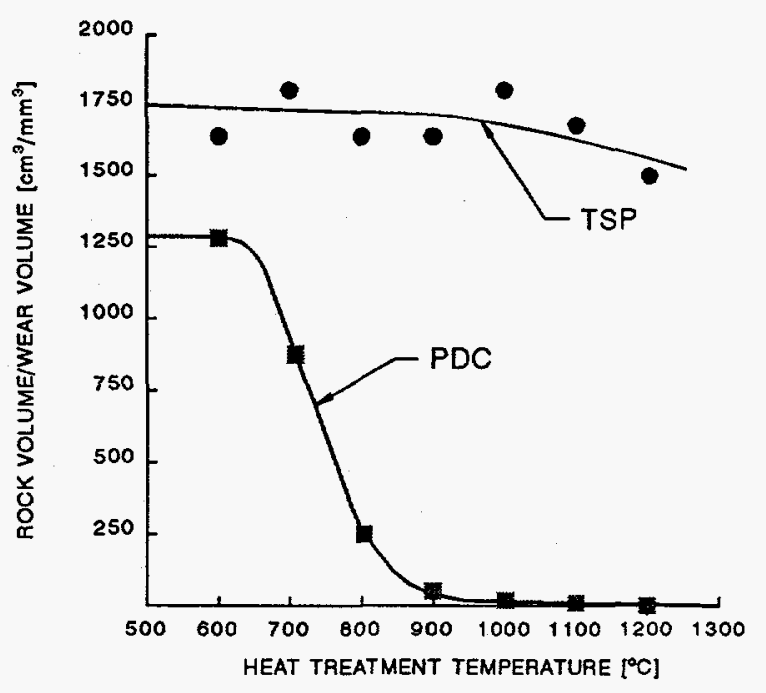

Figure 5. Temperature Effects on PDC and TSP Cutters (Clark et al., 1987)

This decrease in strength of the PDC cutters is due to differences in the thermal expansion of the diamond and the cobalt binder in the void spaces between the diamonds, as shown in Figure 6 . As the cutters are heated, the cobalt binder expands more than the diamonds, causing thermal fracturing and failure of the PDC cutters. 


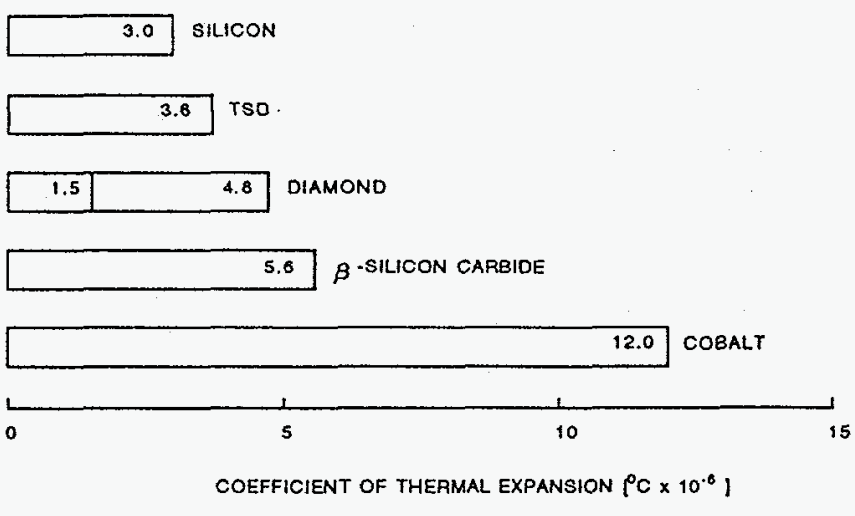

Figure 6. Thermal Coefficient of Expansion (Clark et al., 1987)

TSP cutters contain silicon instead of cobalt in the pore spacers between the diamonds. The silicone binder allows the PDC cutters to operate effectively at high temperatures because the thermal coefficient of expansion of silicon is similar to that of diamond. Consequently, TSP cutters can drill hard rock without excessive wear or breakage of the cutter as shown in Figure 7. In this test, a TSP bit drilled over $300 \mathrm{ft}$. in granite that is much harder than the sedimentary rocks normally encountered in gas wells.

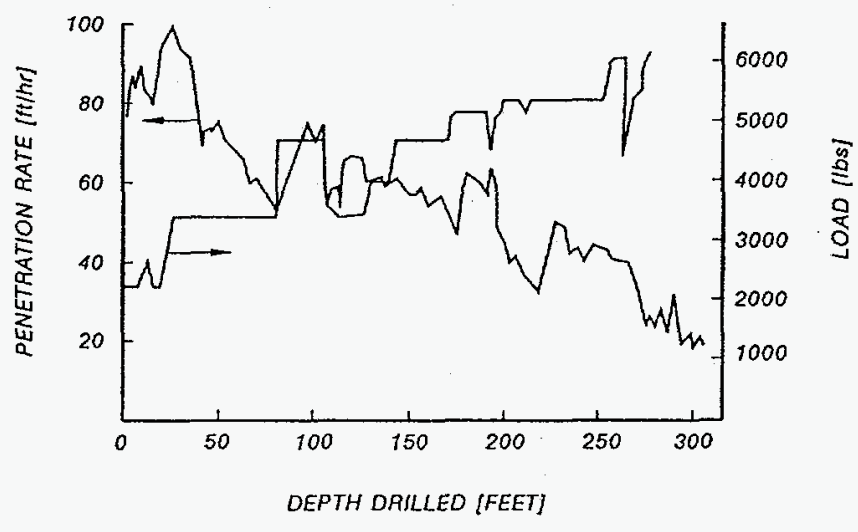

Figure 7. TSP Bit Drilling Granite (Clark et al., 1987)
MEI, in conjunction with The University of California at Berkeley, conducted numerous single cutter and laboratory bit tests varying the number, size, and configuration of TSP cutters. These tests showed that TSP bits utilizing large TSP cutters ( $7 \mathrm{~mm} \times 7 \mathrm{~mm} \times 5 \mathrm{~mm}$ ) drill much faster and further than conventional PDC and TSP bits. Figure 8 shows a large-cutter TSP bit that performed well in laboratory tests.

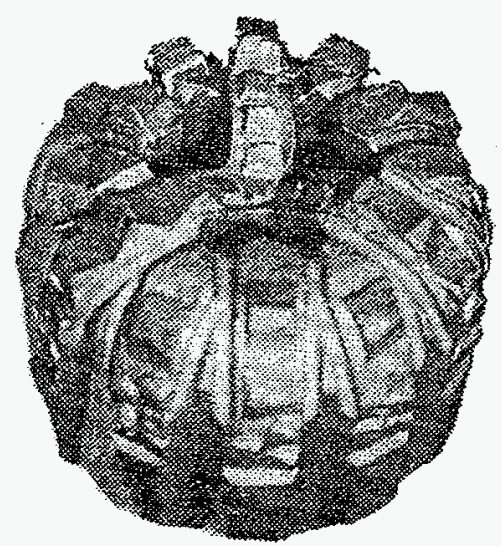

Figure 8. LC-TSP Bit

As part of Phase I, MEI will design LC-TSP bits with torque and speed characteristics that match the high-power motor characteristics, and the lithology of the area to be drilled.

The field motor and bits will be tested on the DRC motor drilling stand (Figure 9). Data from these tests will be used to determine the optimum field operating parameters for the slim-hole drilling system.

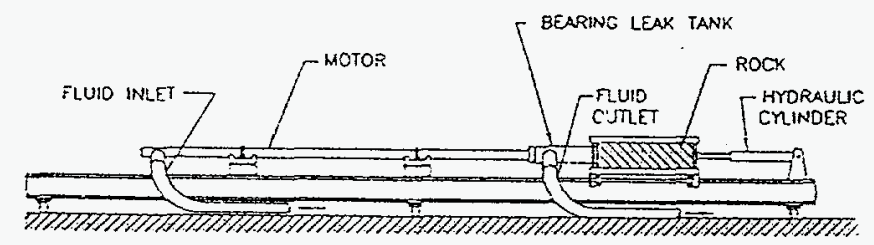

Figure 9. Motor Drilling Stand 


\section{Phase II - Field Tests}

During Phase II, shallow drilling tests $(2500 \mathrm{ft})$ will be conducted at Amoco's Catoosa test site near Tulsa. The results of these shallow tests will be used to optimize the motors and bits prior to conducting full-scale field tests. The field system will then be laboratory tested on the DRC's dynamometer and drilling test stands prior to field tests.

Following the laboratory tests, the slim-hole system will be tested in slim-hole gas wells. A minimum of five tests will be conducted at locations where there is sufficient offset data to make comparisons between conventional drilling and the new high-power slim-hole system. The results of the laboratory and field tests will be submitted to the DOE in a final report.

\section{RESULTS:}

Design of the high-power motor is completed and the modified motor components are being manufactured. Alternative methods of manufacturing the flex high-strength coupling are being studied, including using high-pressure abrasive-jets to cut the lobes on flex coupling since this technique applies no heat to the part, thus eliminating thermal damage produced by flame cutting.

In preliminary tests, the abrasive jet penetrated the steel on the side opposite the cut, damaging the inside of the lobe cut (Figure 10). Attempts are being made to eliminate this problem since the use of this jet-cutting technique looks promising.

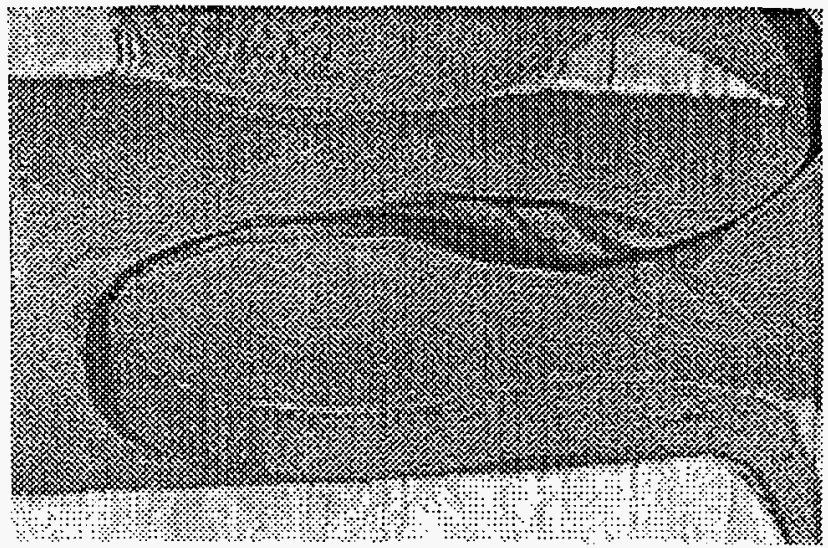

Figure 10. Water Jet Damage on Inside of Cut Coupling

Modifications to the lobe patterns used on these couplings is also being explored to increase the strength and wear resistance of these couplings.

MEI is also examining the use of titanium-flex shafts in place of standard-flex couplings. Robbins and Meyers ran a finite element analysis on a titanium-flex coupling for the high-power motor which shows the stresses for different length flex shafts (Table 1).

Table 1. Flex Shaft Stresses (Robbins \& Meyers)

Assumptions:

1) Rotor Eccentricity $=0.165$ in.

2) Flex due to motor bend $=2.5^{\circ}$

3) Maximum down thrust 5900 lbs

4) Maximum torque $1660 \mathrm{ft}-1 \mathrm{bs}$

5) Titanium bar, $\mathrm{OD}=1.75 \mathrm{in}$.

\begin{tabular}{|c|c|c|}
\hline Length & Bore & Max. Stress (PSI) \\
\hline \hline 24 in. & None & $108 \mathrm{~K}$ \\
24 in. & .75 in. & $112 \mathrm{~K}$ \\
30 in. & None & $70 \mathrm{~K}$ \\
30 in. & .75 in. & $67 \mathrm{~K}$ \\
36 in. & None & $42 \mathrm{~K}$ \\
36 in. & .75 in & $38 \mathrm{~K}$ \\
\hline
\end{tabular}


The endurance limit for titanium is $40 \mathrm{ksi}$ so a shaft 1.75 in. $x .75$ in. diameter 36 in. long should give infinite life at the predicted maximum load conditions. The length added by the flex shaft is small compared to the newer length of the highpower motor.

\section{FUTURE WORK:}

The high-power motor will be assembled and tested as soon as all motor components are manufactured.

Torque tests of different design flex couplings will be conducted up to the failure load using a rotary torque machine. The best coupling design will be selected for laboratory testing in the high-power motor. Design of the flex shaft will be completed and manufacture begun. Prototype flex couplings and flex shafts will be tested on the dynamometer test stand to determine their effect on motor performance.

MEI will develop a test plan for the dynamometer and drilling tests while manufacture of the motor is completed. Dynamometer testing of the motor will be carried out to determine motor torque, speed, power output, and efficiency. The largecutter TSP field bits will be designed and manufactured after the field sites are selected and the bit sizes and the lithology determined.

Drilling tests will be conducted with the highpower motors and LC-TSP bits before field tests are conducted.

\section{REFERENCES:}

Clark, I.E. and Shafto, G.R., 1987: "Core Drilling With SYNDAX3 PCD," Industrial Diamond Review, April.
Delpassand, Majid, 1995: Personal Communication, Moyno Oilfied Products (A Division of Robbins and Meyers, Inc.), Fairfield, California. 